\title{
Simulation of Cross-Border Renewable Energy Trading in South Asia
}

Mohit Joshi

David Hurlbut

David Palchak

June 2020 


\section{Study Objective}

2 Scenarios Modeled

3 About the South Asia model

4 Implications for Bangladesh

5 Implications for Sri Lanka

6 Implications for Nepal

7 Implications for India

8 Summary

9 Additional Research

References 
- To assess the impact of cross-border renewable energy (RE) trading in South Asia:

- $1 \mathrm{GW}$ solar or wind contract from South India (Tamil Nadu) to Bangladesh or Sri Lanka

- $1 \mathrm{GW}$ hydro contract from Nepal to Bangladesh.

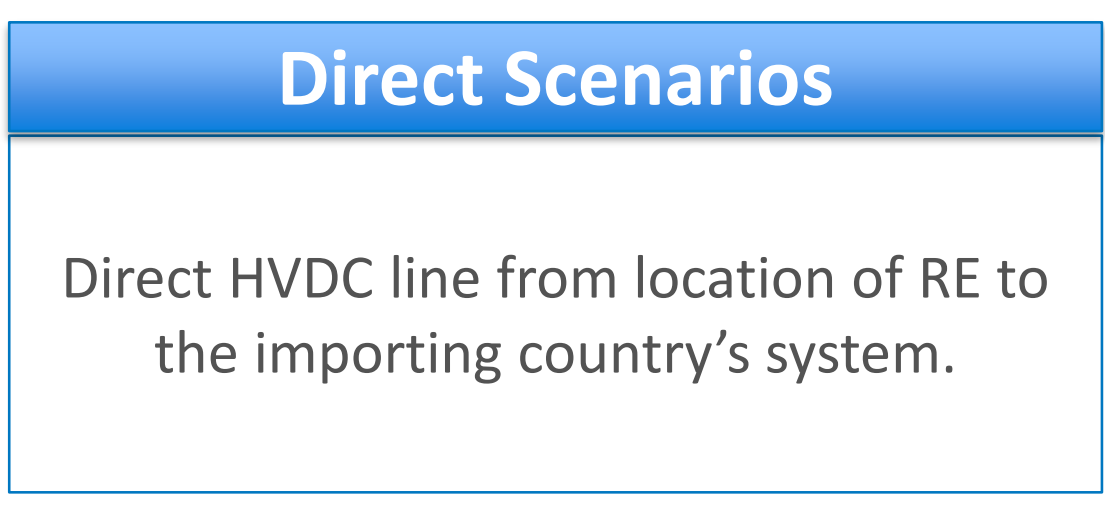

\section{Indirect Scenarios}

Wheeling of RE through the Indian grid to an expanded DC tie between West Bengal and Bangladesh. 


\section{Scenarios Modeled}

\section{Scenario}

Base Case

IN-BD-WIND-DIRECT

IN-BD-SOLAR-DIRECT

IN-SL-WIND-DIRECT

IN-SL-SOLAR-DIRECT

IN-BD-WIND-INDIRECT

IN-BD-SOLAR-INDIRECT

NP-BD-HYDRO-DIRECT

NP-BD-HYDRO-INDIRECT

The study looked at the operational costs only; comparisons between scenarios do not account for capital costs such as new transmission lines or expanding the West Bengal to Bangladesh HVDC tie.

\section{Description}

2022 Scenario. India, Bangladesh, Nepal, Bhutan interconnected

Base Case + New 1 GW Wind in Tamil Nadu + HVDC from Tamil Nadu to Bangladesh Base Case + New 1 GW Solar in Tamil Nadu + HVDC from Tamil Nadu to Bangladesh

Base Case + New 1 GW Wind in Tamil Nadu + HVDC from Tamil Nadu to Sri Lanka Base Case + New 1 GW Solar in Tamil Nadu + HVDC from Tamil Nadu to Sri Lanka

Base Case + New 1 GW Wind in Tamil Nadu + HVDC from West Bengal to Bangladesh Base Case + New 1 GW Solar in Tamil Nadu + HVDC from West Bengal to Bangladesh Base Case + New 1 GW Hydro in Nepal + HVDC from Nepal to Bangladesh Base Case + New 1 GW Hydro in Nepal + HVDC from West Bengal to Bangladesh 


\section{About the South Asia Model}

\section{India}

1. Detailed representation of conventional and renewable generation and transmission[1];

2. Transmission aggregated at state level for this study;

3. New wind/solar in India (Tamil Nadu) generation profile was based on average profile of the state;

4. India-Bangladesh existing HVDC flow fixed to 1,000 MW

5. Flow on new HVDCs in different scenarios fixed corresponding to the generation pattern of new renewables (solar/wind/hydro).

\section{Nepal}

1. Detailed representation of generation and transmission [2][3]

2. Transmission aggregated at country level for this study; and

3. New hydro generator in Nepal given average profile of Karnali basin run of river (ROR) hydro dispatch in base case.

\section{Bangladesh}

1. Aggregated transmission model prepared for this study;

2. Detailed representation of all generators [4]

3. Bangladesh load shape same as of 2018 [5]

4. Bangladesh energy forecasted based on past years data.

\section{Sri Lanka}

1. Detailed representation of conventional and renewable generation and transmission [6]

2. Transmission aggregated at country level for this study.

\section{Bhutan}

1. Detailed representation of generation and transmission[1]

2. Bhutan model improved with addition of load profile and updated energy limits for hydro[7]. 
Generation Mix in South Asia (Base Case, 2022)

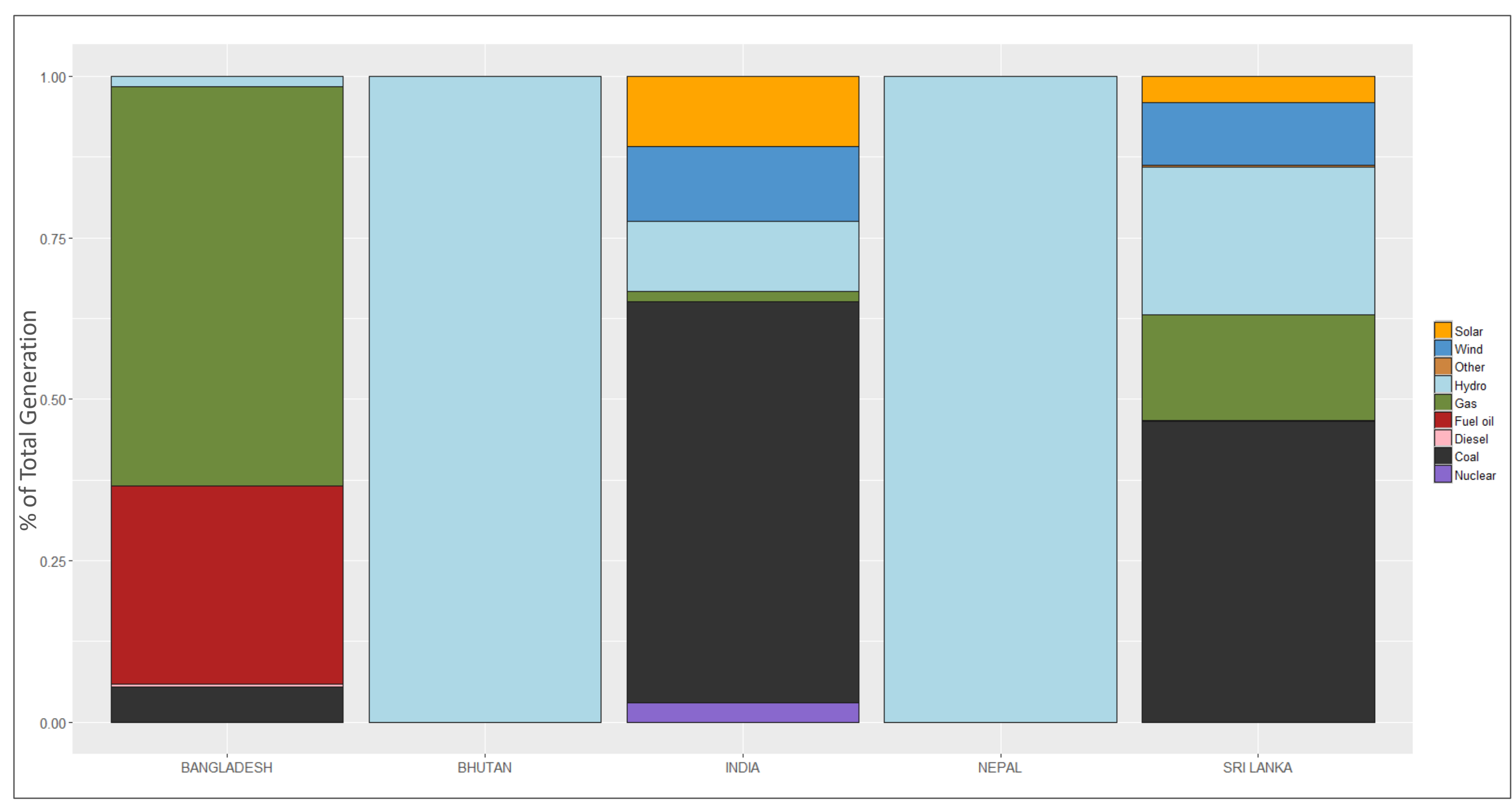


Correlation: Load in Bangladesh, Sri Lanka with Wind, Solar in Tamil Nadu, and Hydro in Nepal

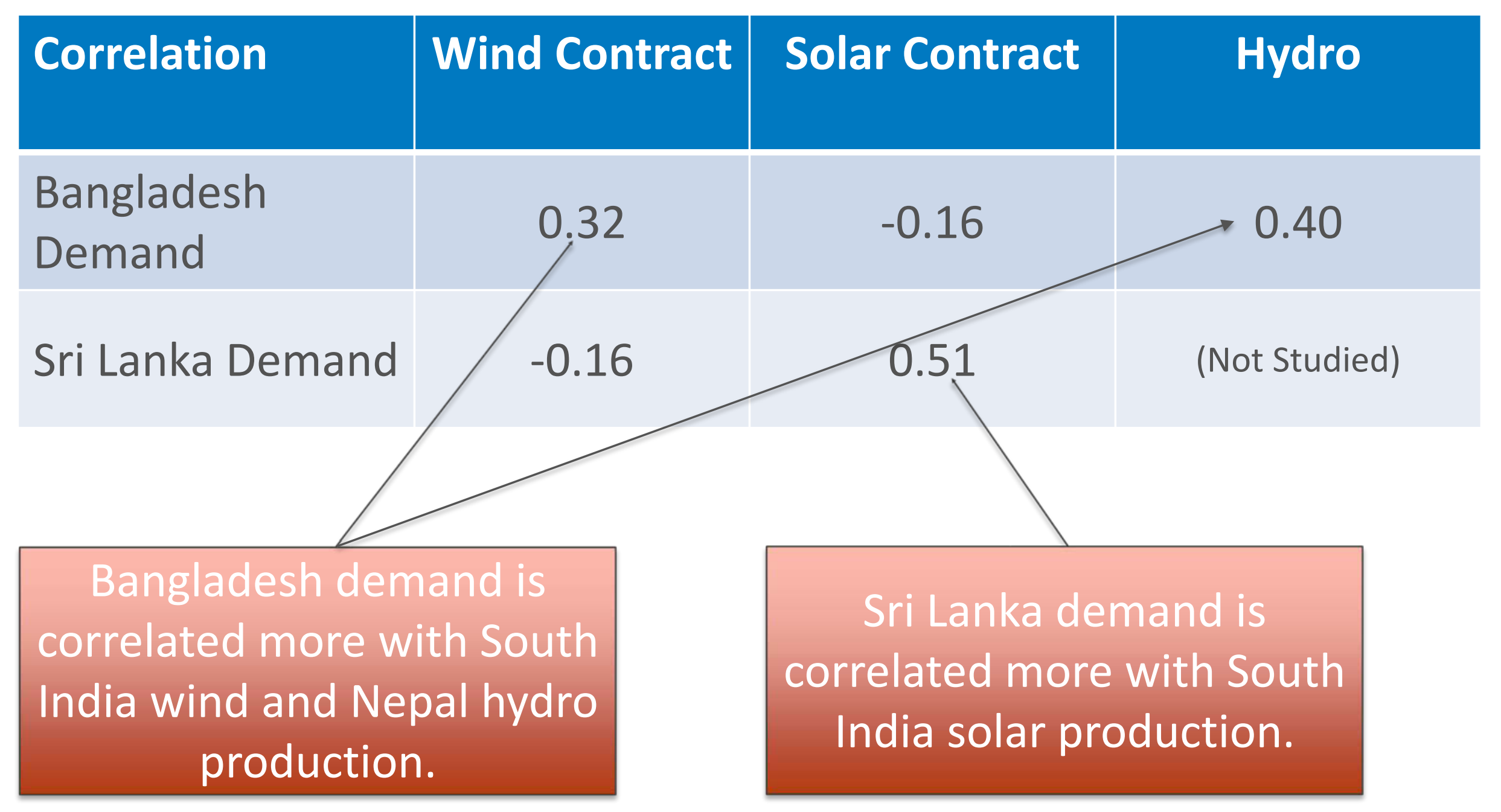


Bangladesh and Sri Lanka Demand Correlation with Wind and Solar: Seasonal

\begin{tabular}{|c|c|c|c|c|}
\hline & Sri Lanka load - solar & Bangladesh load - wind & Bangladesh load - hydro & \multirow{9}{*}{$\begin{array}{l}\text { The correlation of Nepal } \\
\text { Hydro with Bangladesh Load } \\
\text { is more seasonal than } \\
\text { hourly, hence high annual } \\
\text { correlation than monthly } \\
\text { correlation. }\end{array}$} \\
\hline Jan & 0.53 & 0.16 & 0.04 & \\
\hline Feb & 0.53 & 0.35 & 0.13 & \\
\hline Mar & 0.59 & 0.47 & 0.16 & \\
\hline Apr & 0.50 & 0.15 & 0.05 & \\
\hline May & 0.55 & 0.35 & 0.17 & \\
\hline Jun & 0.51 & -0.08 & 0.24 & \\
\hline Jul & 0.54 & 0.17 & 0.20 & \\
\hline Aug & 0.51 & 0.30 & 0.12 & \\
\hline Sep & 0.48 & 0.07 & 0.18 & \multirow{6}{*}{$\begin{array}{c}\text { The correlation of Tamil } \\
\text { Nadu Wind with Bangladesh } \\
\text { load is more hourly than } \\
\text { seasonal. }\end{array}$} \\
\hline Oct & 0.54 & 0.11 & 0.15 & \\
\hline Nov & 0.49 & 0.09 & 0.05 & \\
\hline Dec & 0.42 & 0.15 & 0.19 & \\
\hline Annual & 0.51 & 0.32 & 0.40 & \\
\hline & $\begin{array}{l}\text { ation is consistent } \\
\text { ughout the year. }\end{array}$ & \multicolumn{2}{|c|}{ High seasonal correlation } & \\
\hline
\end{tabular}




\section{Implications for Bangladesh (Importing Solar from Tamil Nadu, India)}

Importing $1 \mathrm{GW}$ of Tamil Nadu solar power replaces 1.5 TWh of domestic generation annually at a savings of $\$ 158$ per MWh replaced

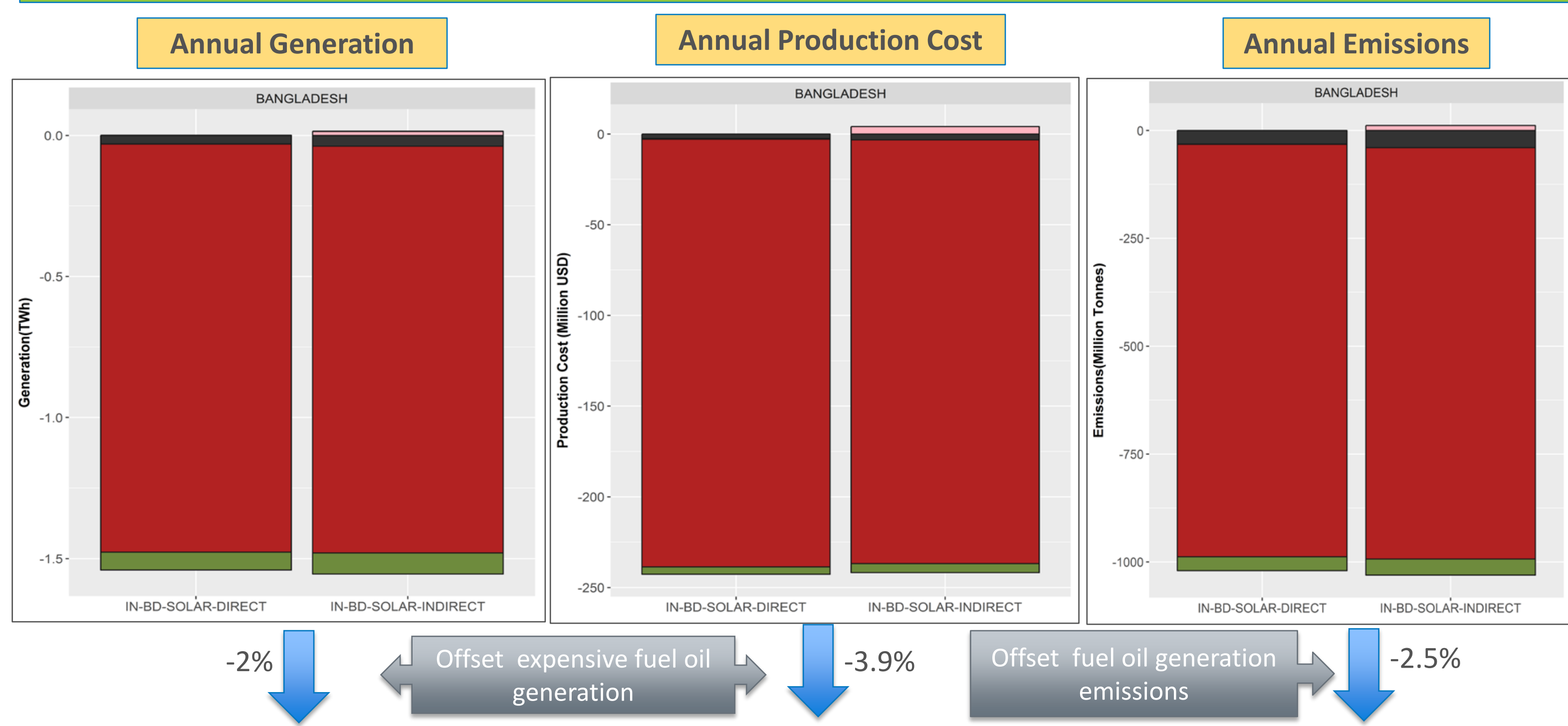

Note : All the numbers are with reference to Base Case. Since the difference between DIRECT and INDIRECT scenario is very small, \% change represents numbers for DIRECT scenario only. NATIONAL RENEWABLE ENERGY LABORATORY 


\section{Implications for Bangladesh (Importing Hydro from Nepal)}

$1 \mathrm{GW}$ of Nepal hydropower offset 5.5 TWh domestic generation annually in Bangladesh at a savings of \$168/MWh for the energy replaced

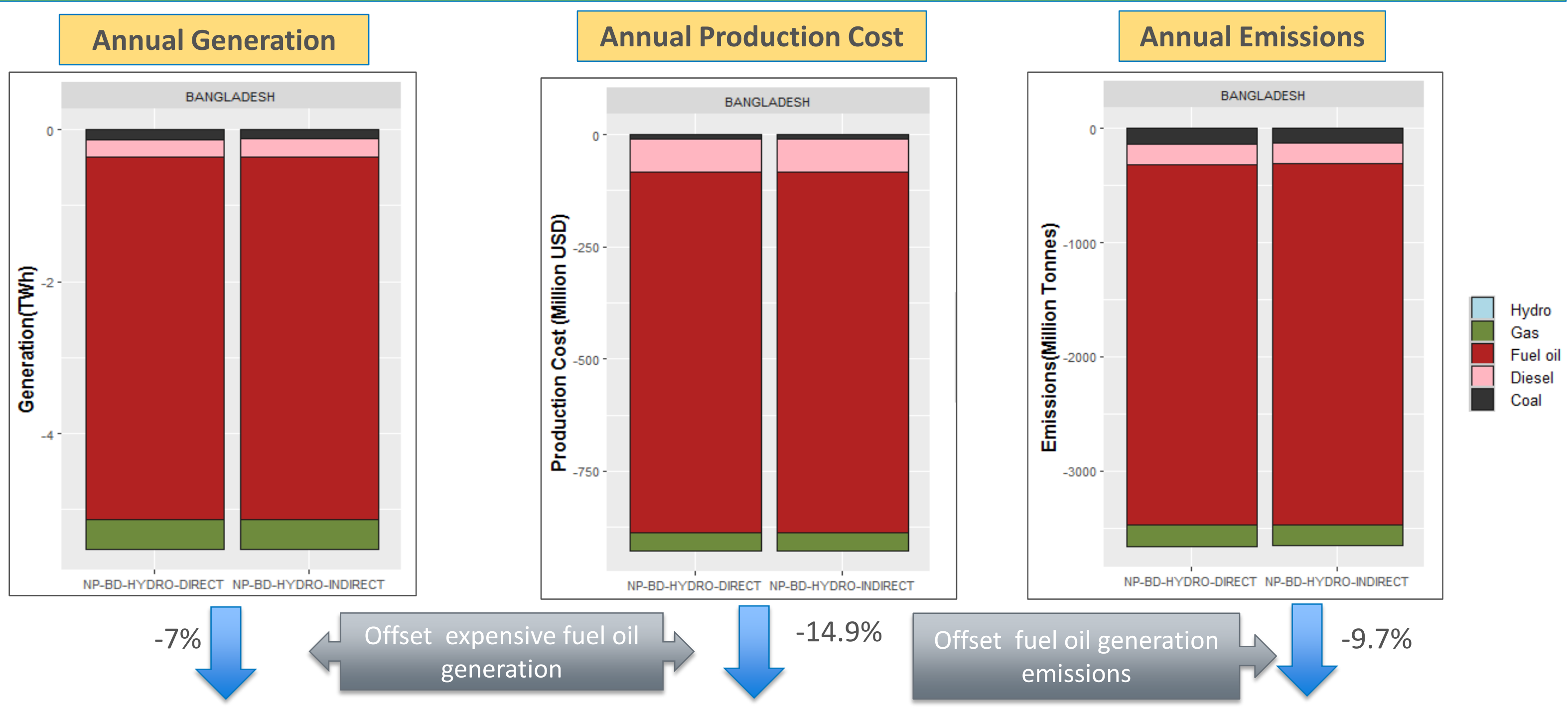

Note : All the numbers are with reference to Base Case. Since the difference between DIRECT and INDIRECT scenario is very small, \% change represents numbers for DIRECT scenario only. NATIONAL RENEWABLE ENERGY LABORATORY 


\section{Implications for Bangladesh (Cost Reductions)}

\section{Production Cost Savings Per Unit of Generation Reduced}

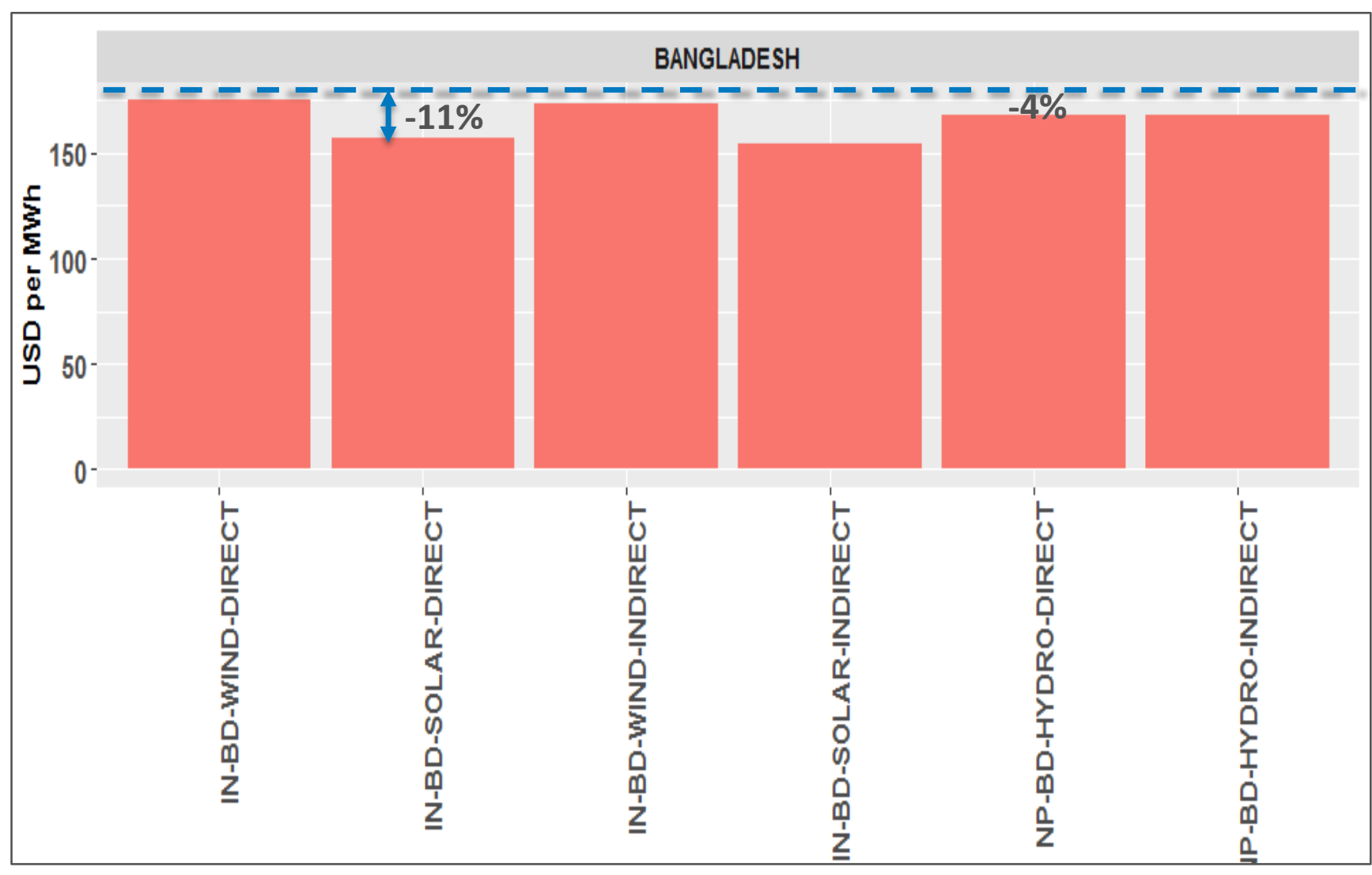

Savings per unit energy displaced (\$/MWh)

\begin{tabular}{lll}
\hline Wind & 175 & \\
\hline Solar & 158 & $-11 \%$ \\
\hline Hydro & 168 & $-4 \%$ \\
\hline
\end{tabular}

$\checkmark$ Wind is $11 \%$ more valuable than solar and $4 \%$ more than hydro for Bangladesh (in terms of production cost savings per unit of generation reduced);

$\checkmark$ Wind has around 0.32 correlation with Bangladesh demand;

$\checkmark$ Marginal cost high during evening peak (18-22 hrs); and

$\checkmark$ Wind generation available during evening displaces marginal generation that is more costly than the marginal generation replaced by solar during the day. 


\section{Implications for Bangladesh (Change in Dispatch - Highest Demand Day)}

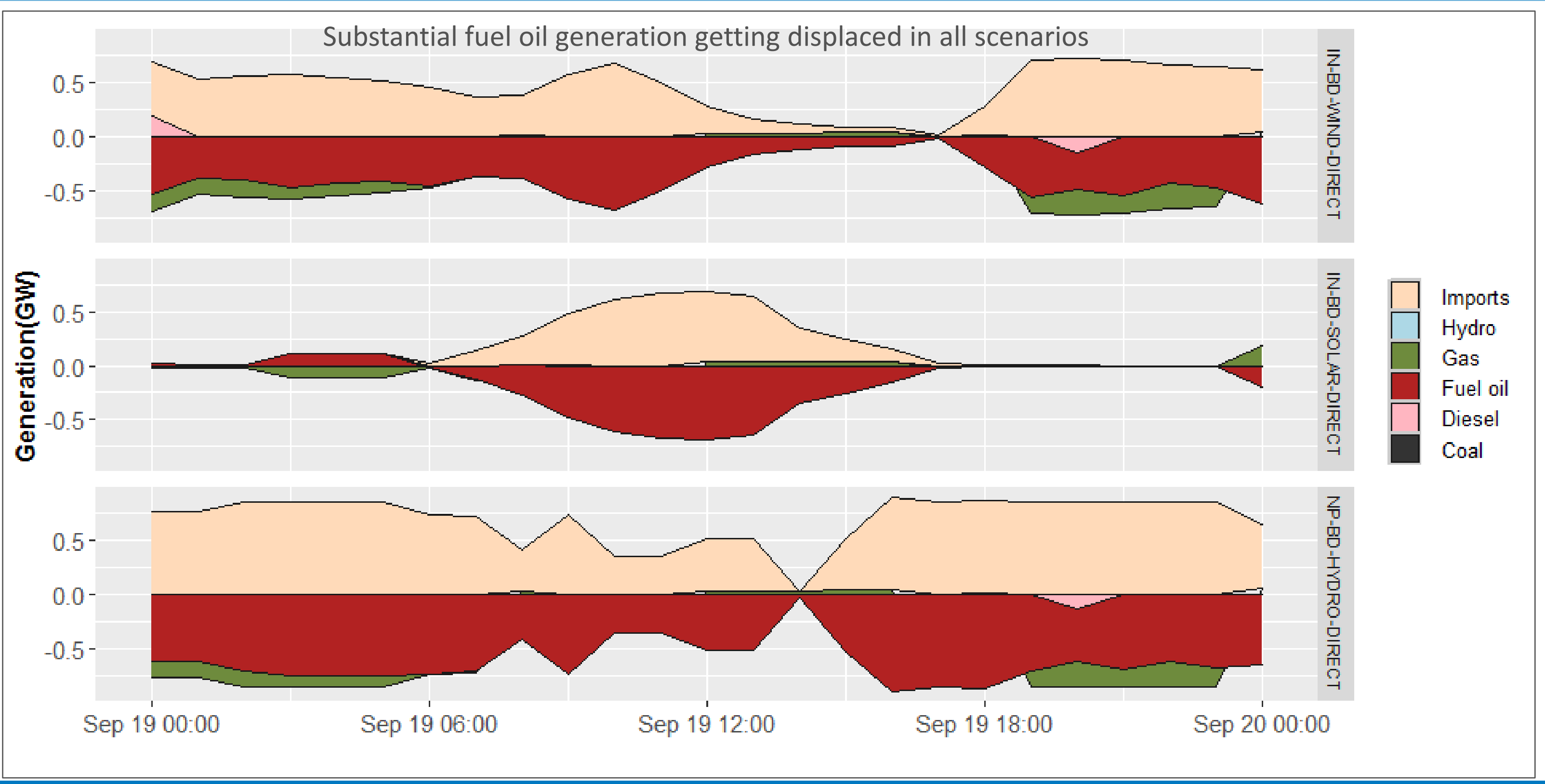




\section{Implications for Bangladesh (Change in Dispatch - Highest Solar Import Day)}

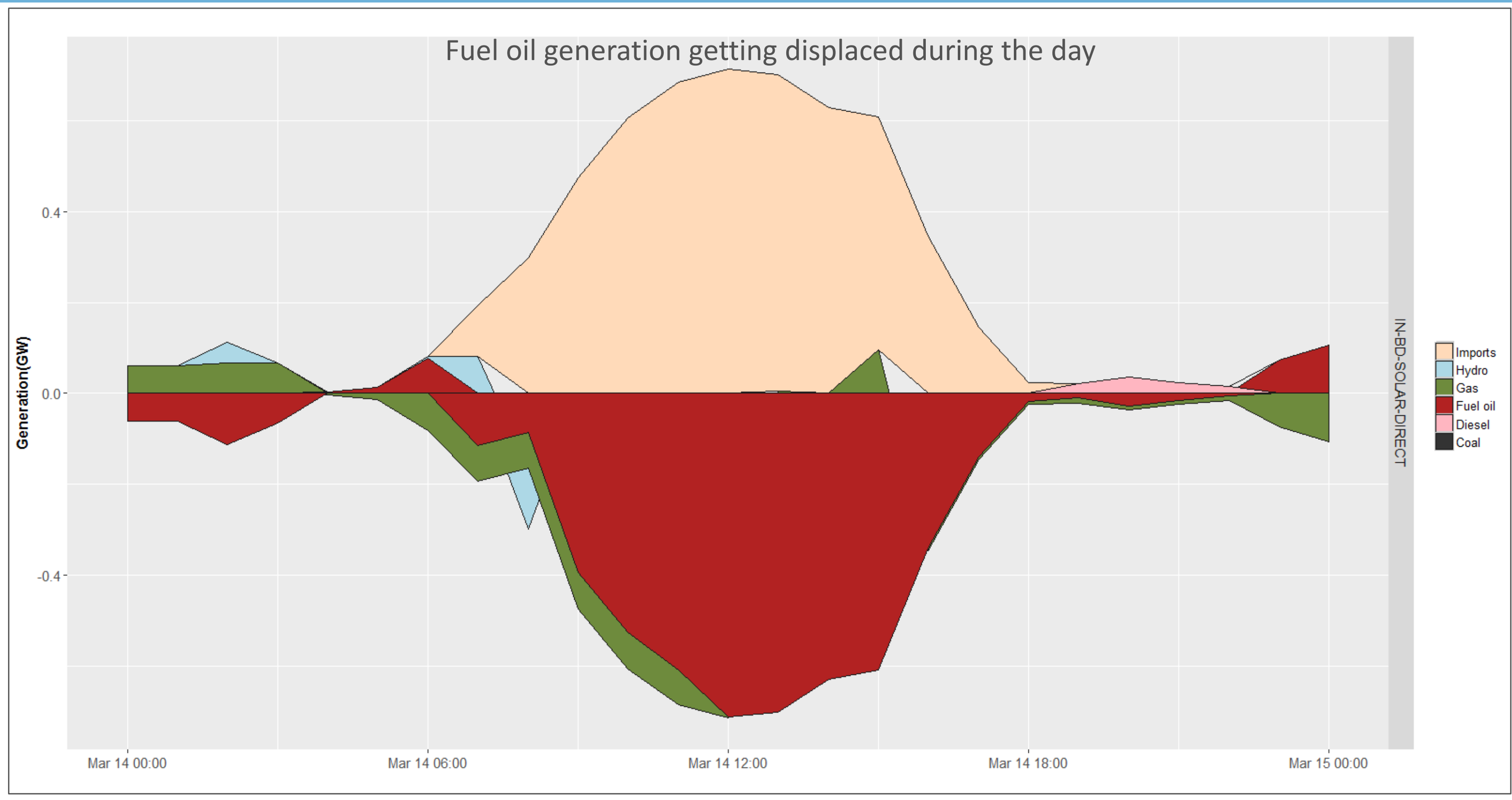


Implications for Bangladesh (Change in Dispatch - Highest Wind Import Day(s))

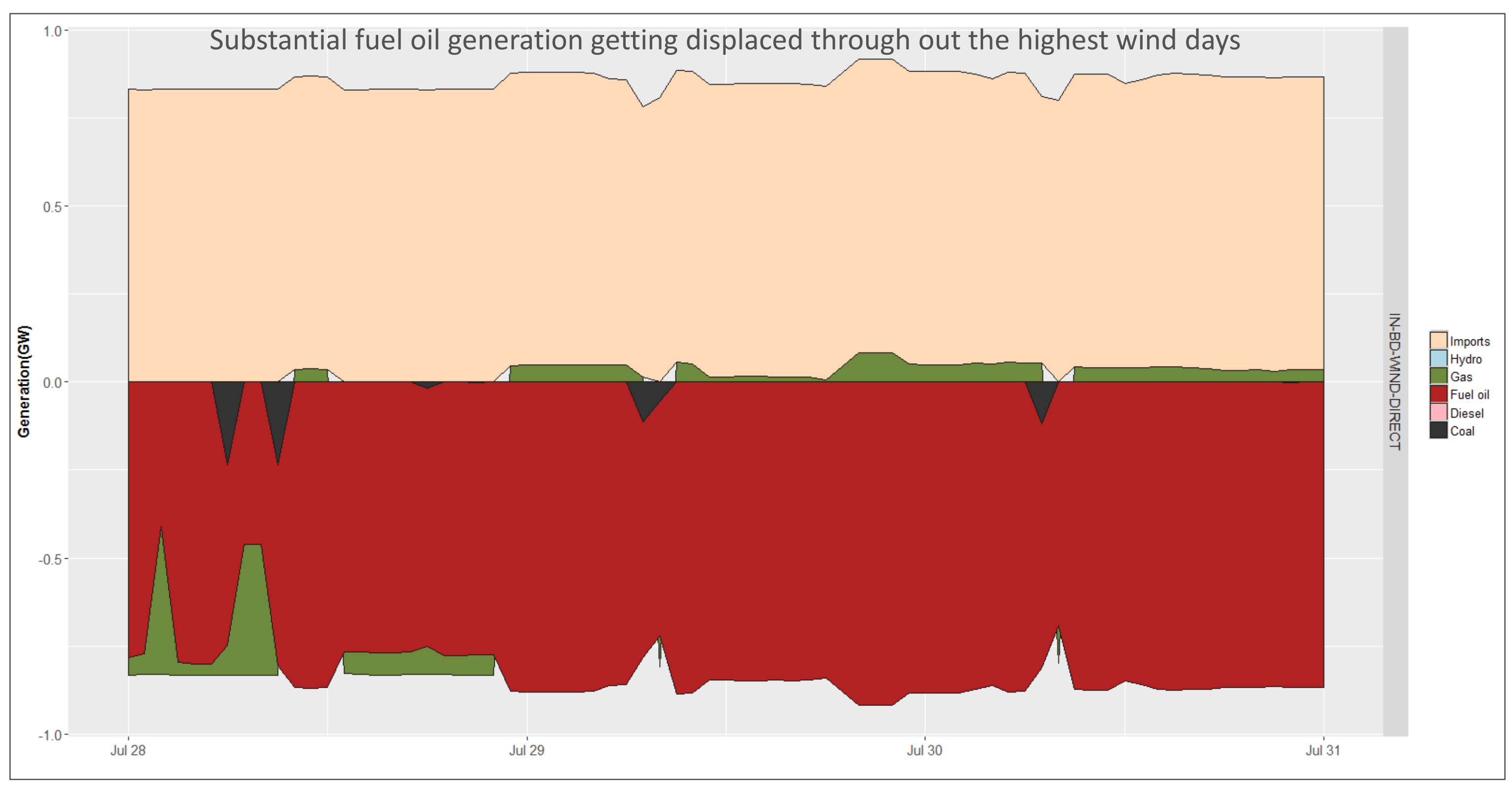




\section{Implications for Sri Lanka (Importing Wind from Tamil Nadu, India)}

Importing $1 \mathrm{GW}$ of Tamil Nadu wind power replaces 3.2 TWh of domestic generation annually at a savings of $\$ 62$ per MWh replaced
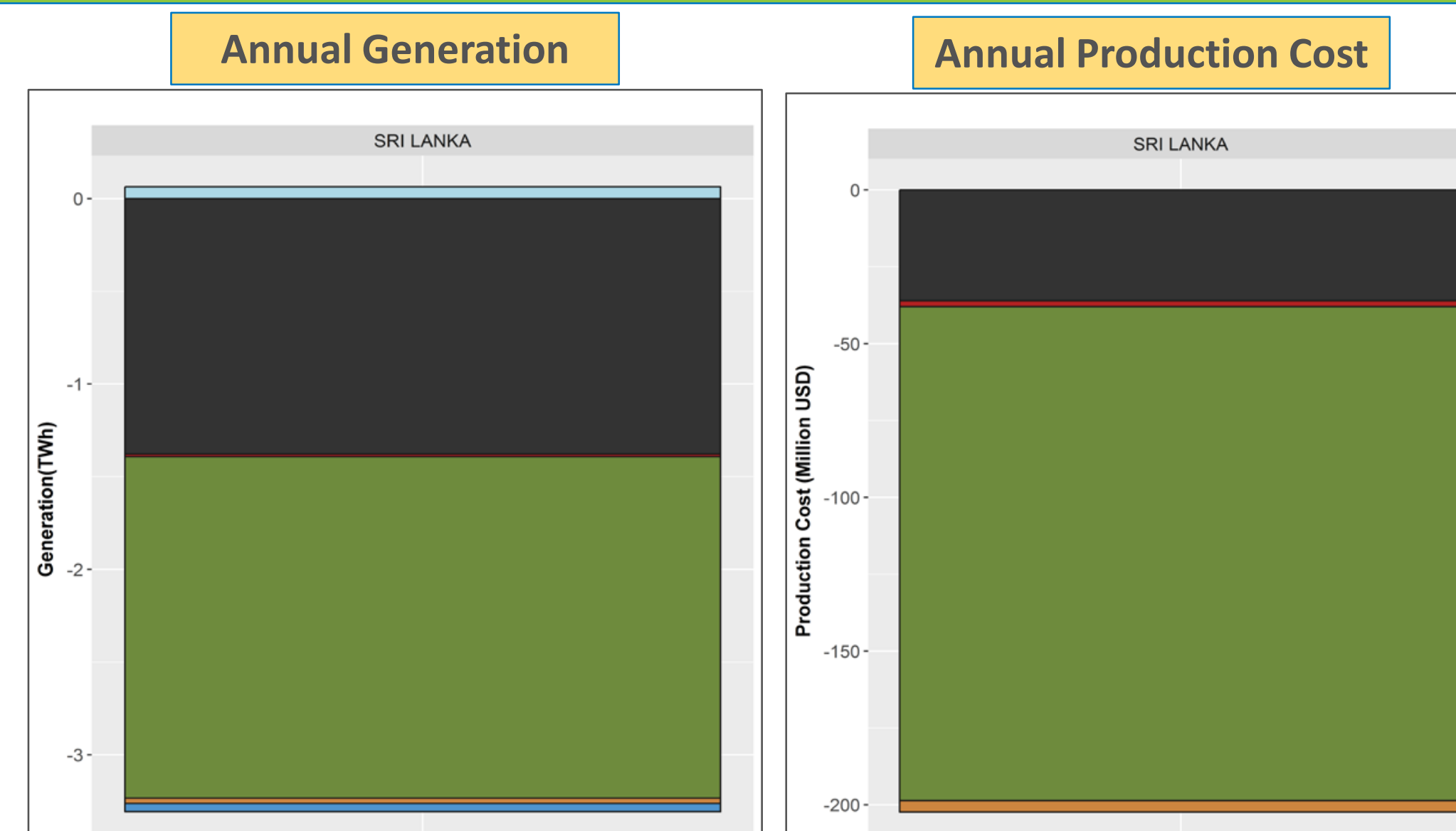

IN-SL-WIND-DIRECT

IN-SL-WIND-DIRECT

Annual Emissions

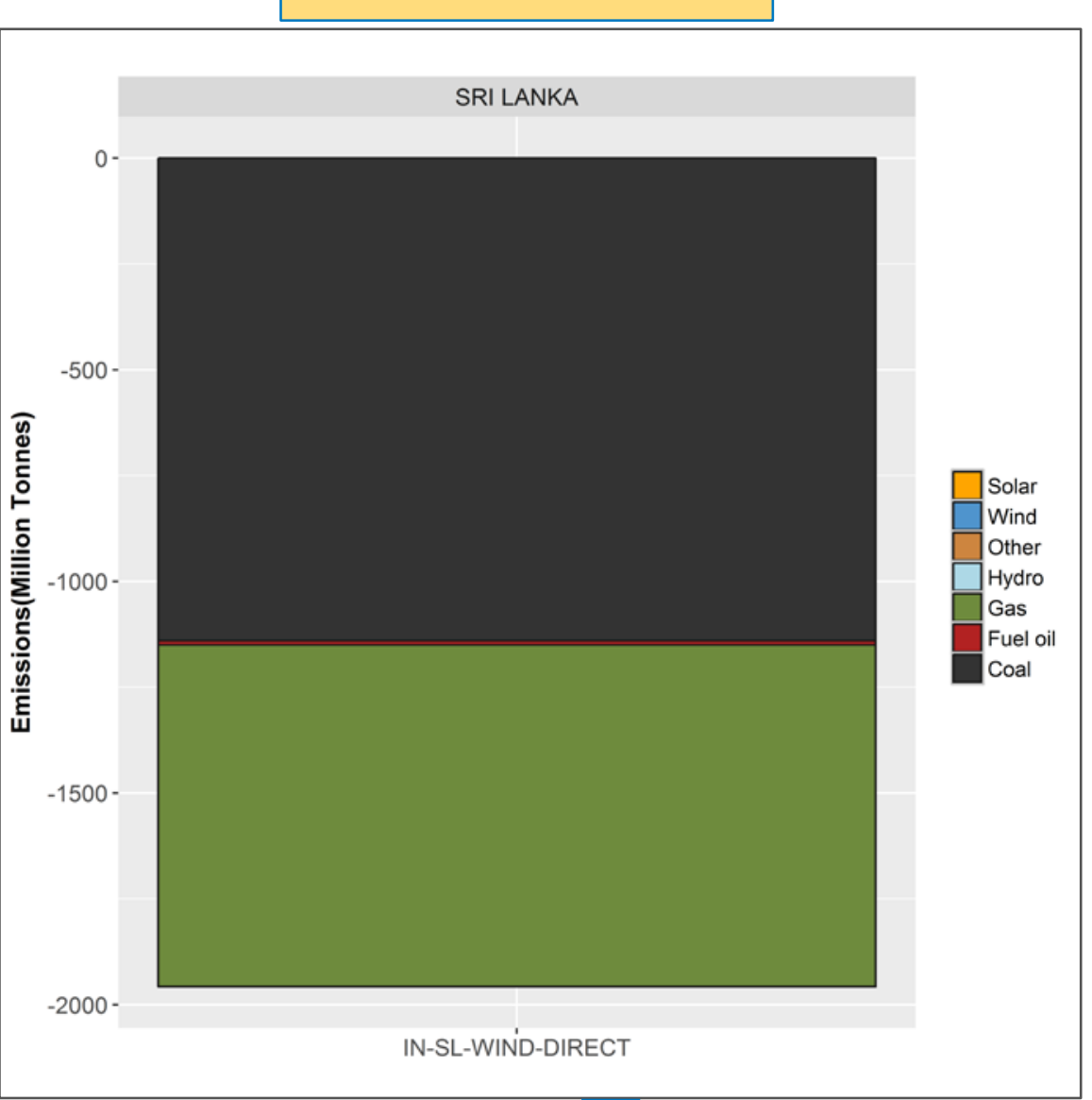

$\int^{-21 \%}$




\section{Implications for Sri Lanka (Importing Solar from Tamil Nadu, India)}

Importing $1 \mathrm{GW}$ of Tamil Nadu solar power replaces 1.6 TWh of domestic generation annually at a savings of $\$ 80$ per MWh replaced

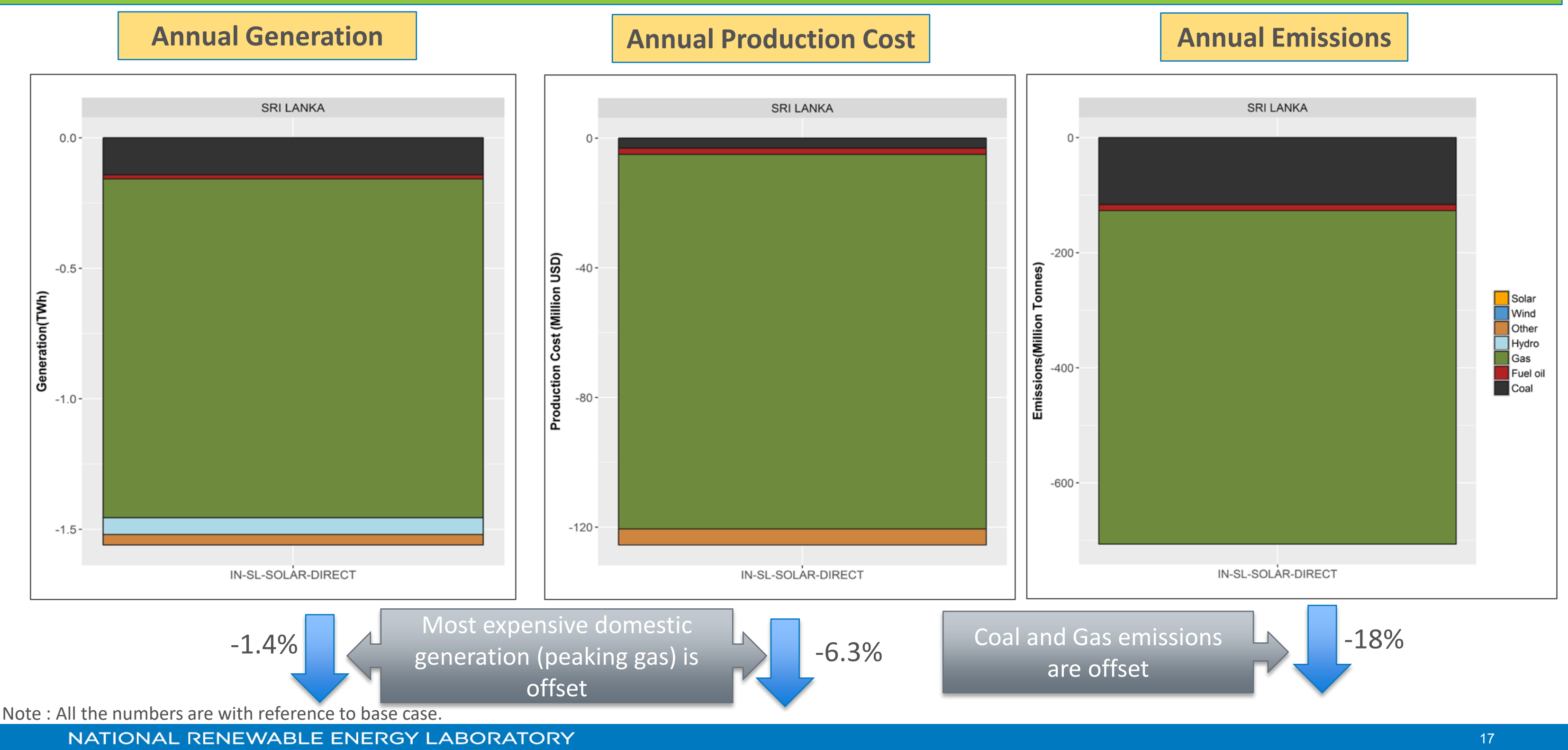




\section{Implications for Sri Lanka (Cost Reductions)}

\section{Production Cost Savings Per Unit of Generation Reduced}

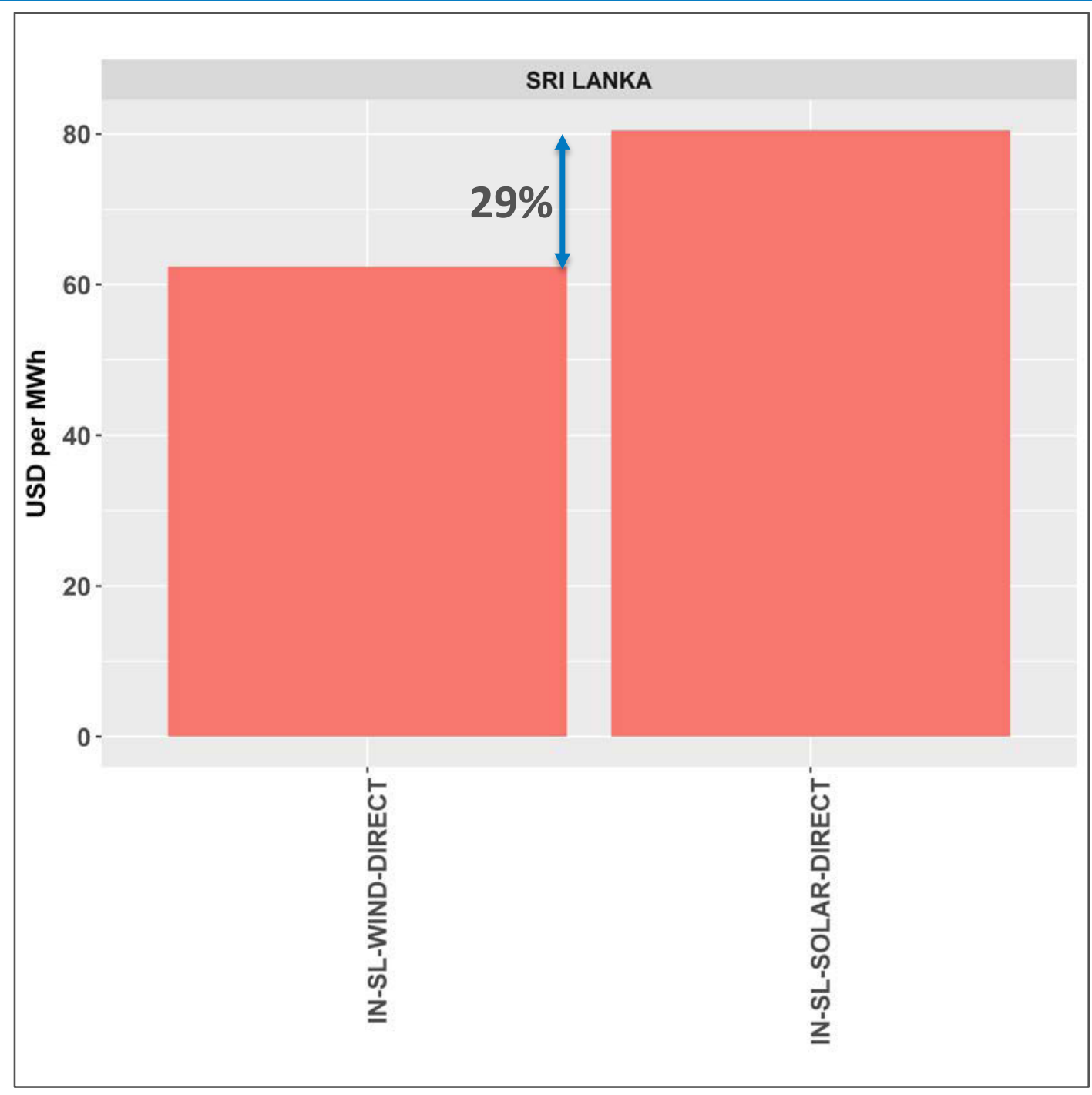

Solar is $29 \%$ more valuable than wind for Sri Lanka (in terms of production cost savings per unit of generation reduced);

$\checkmark$ Solar has around 0.51 correlation with Sri Lanka demand;

$\checkmark$ Marginal cost high during the day, but varies by month;

$\checkmark$ Wind generation is high around the clock during June-August only;

$\checkmark$ During other months, wind generally high during evening/night hours;

$\checkmark$ Solar available between sunrise and sunset yearround; and

$\checkmark$ Solar displaces marginal generation that is more costly than the marginal generation displaced by wind. 


\section{Implications for Sri Lanka (Change in Dispatch - Highest Demand Day)}

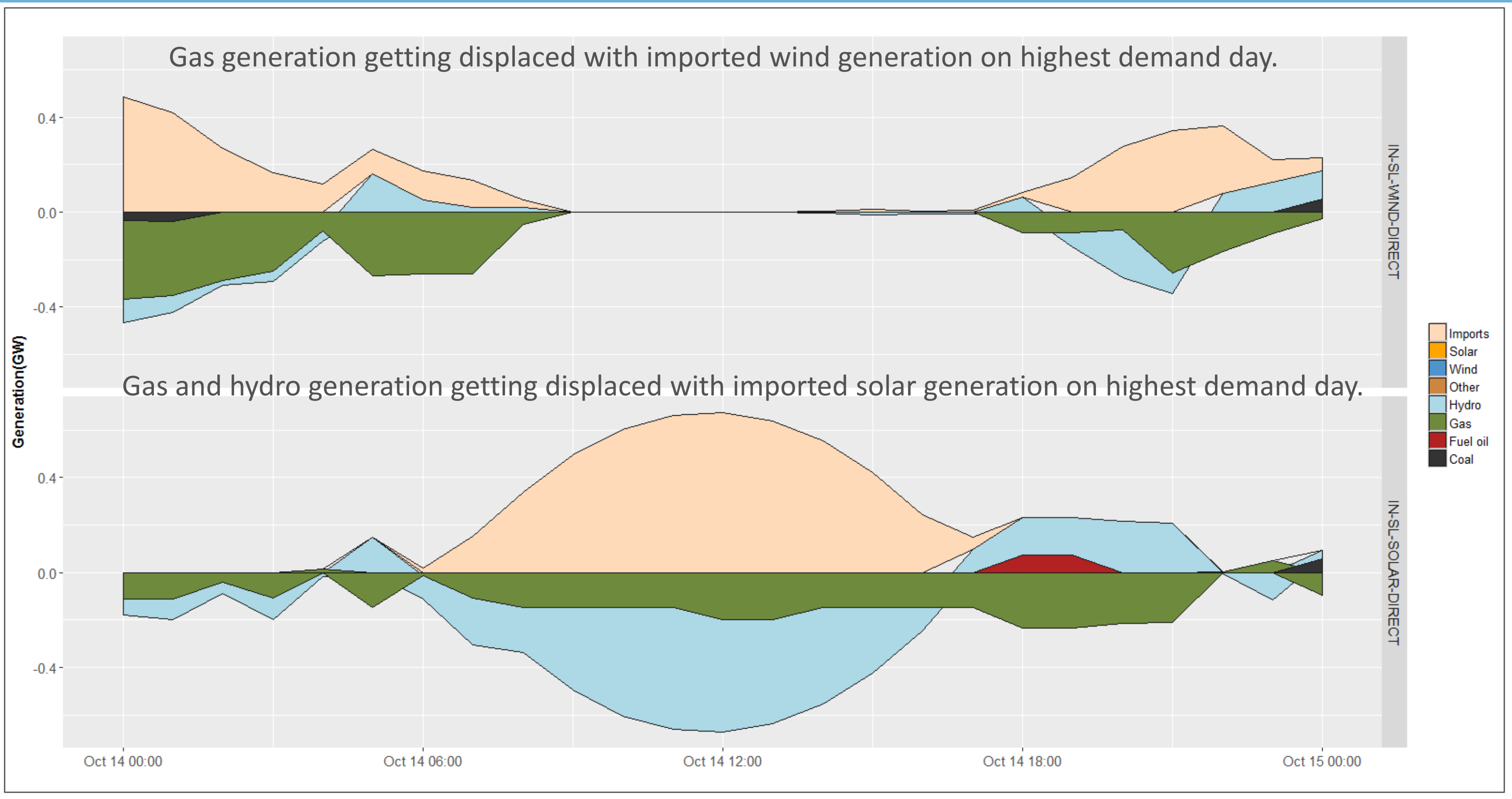




\section{Implications for Sri Lanka (Change in Dispatch - Highest Solar Day)}

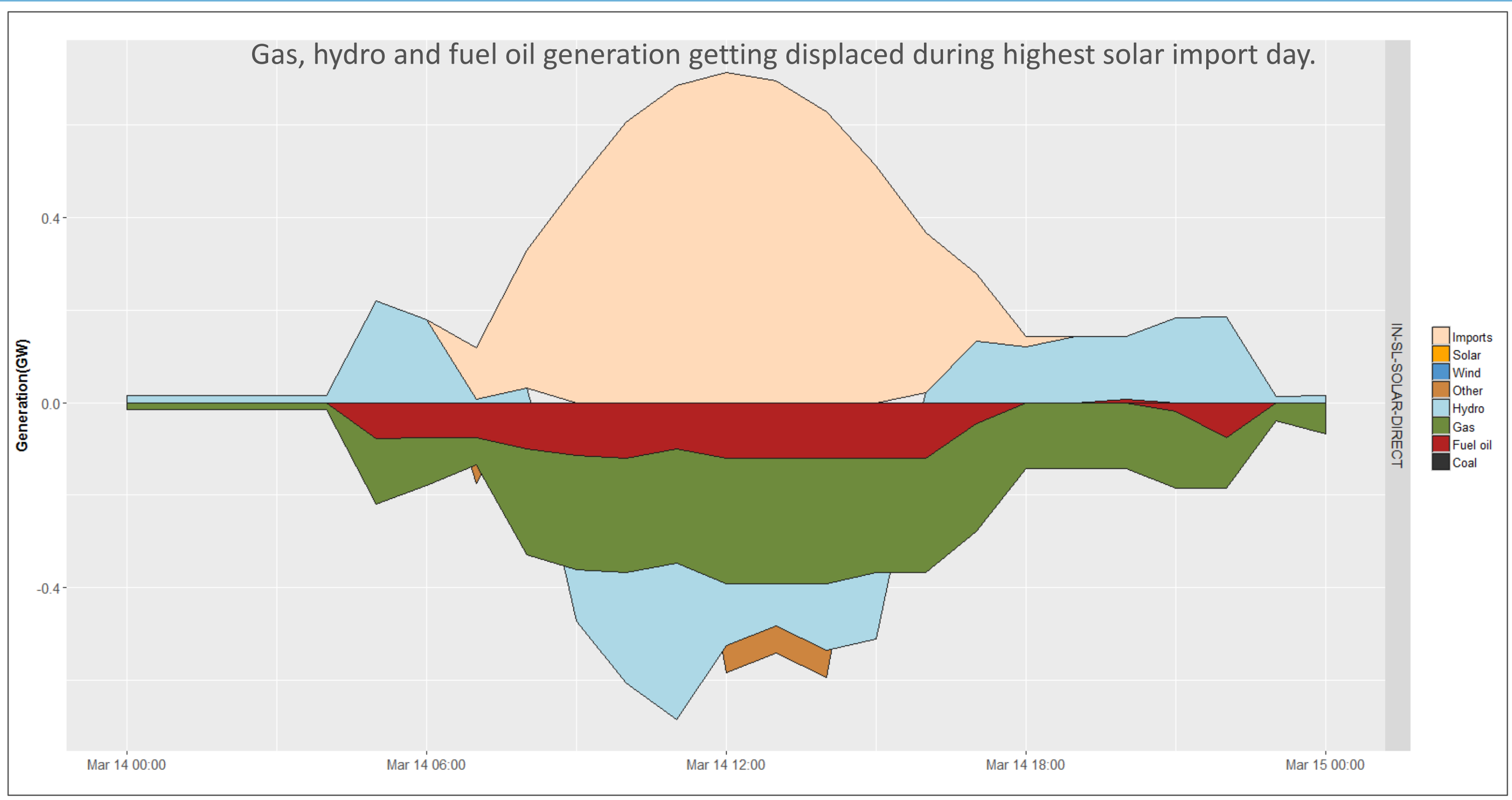




\section{Implications for Sri Lanka (Change in Dispatch - Highest Wind Day(s))}

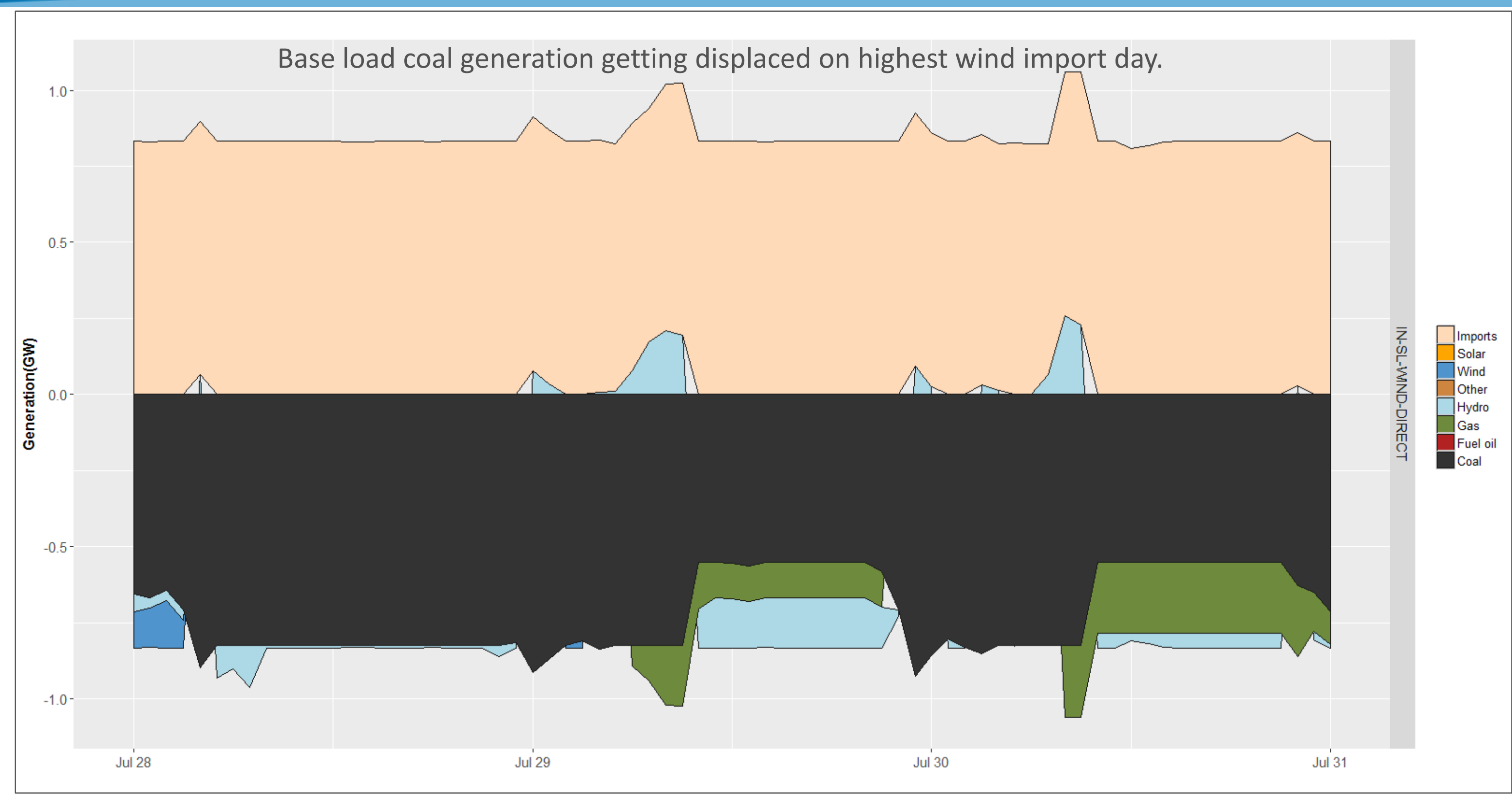

NATIONAL RENEWABLE ENERGY LABORATORY 
- Previous National Renewable Energy Laboratory (NREL) studies have supported the importance of cross-border energy trade (CBET) in reducing curtailment of hydro power in Nepal [2] [3]; and

- Wheeling Nepal hydropower across India's inter state transmission system (ISTS) preserves almost all of the benefits, provided that multilateral participation in the Indian wholesale power market is unobstructed by other national policies. 


\section{Implications for India}

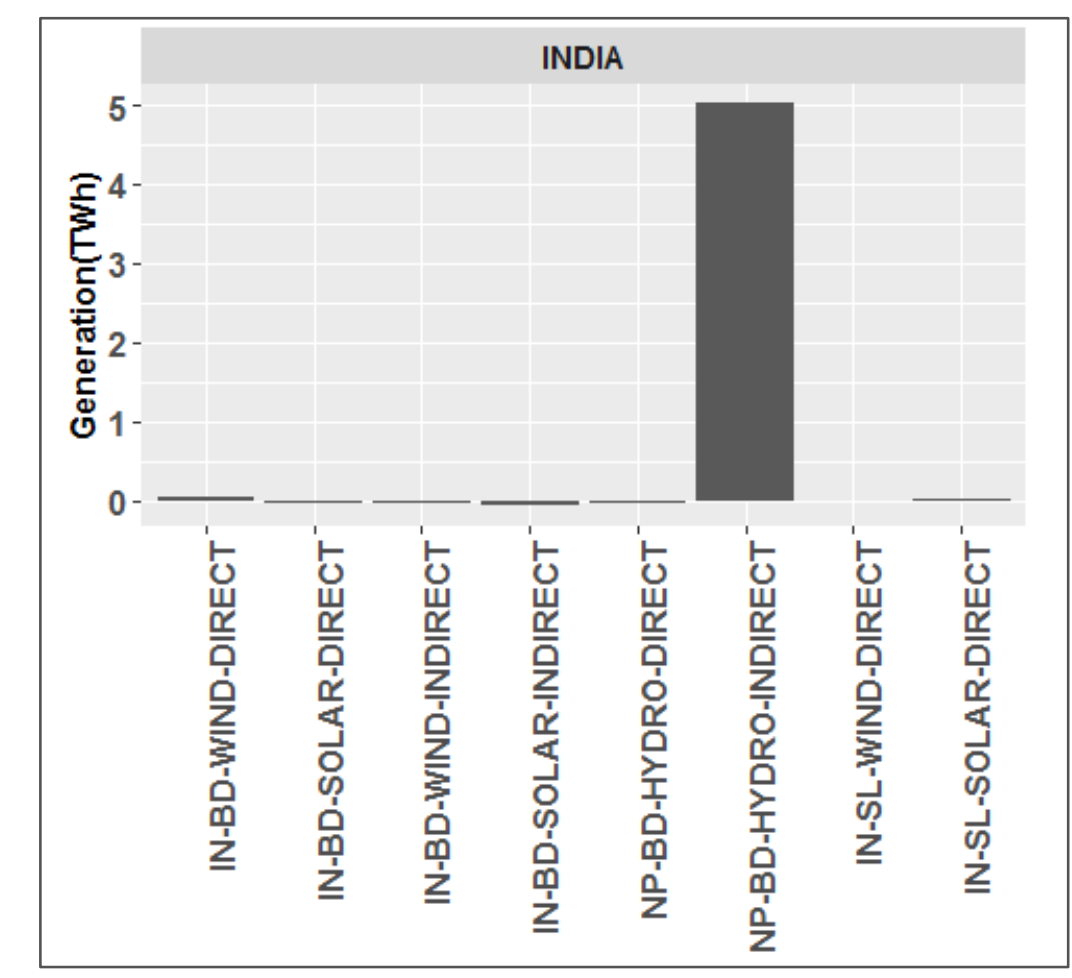

Negligible change in generation in all scenarios for India in comparison to base case generation of around 1,645 TWh.

(5-TWh increase in NP-BD-HydroINDIRECT case is only $0.3 \%$ of total
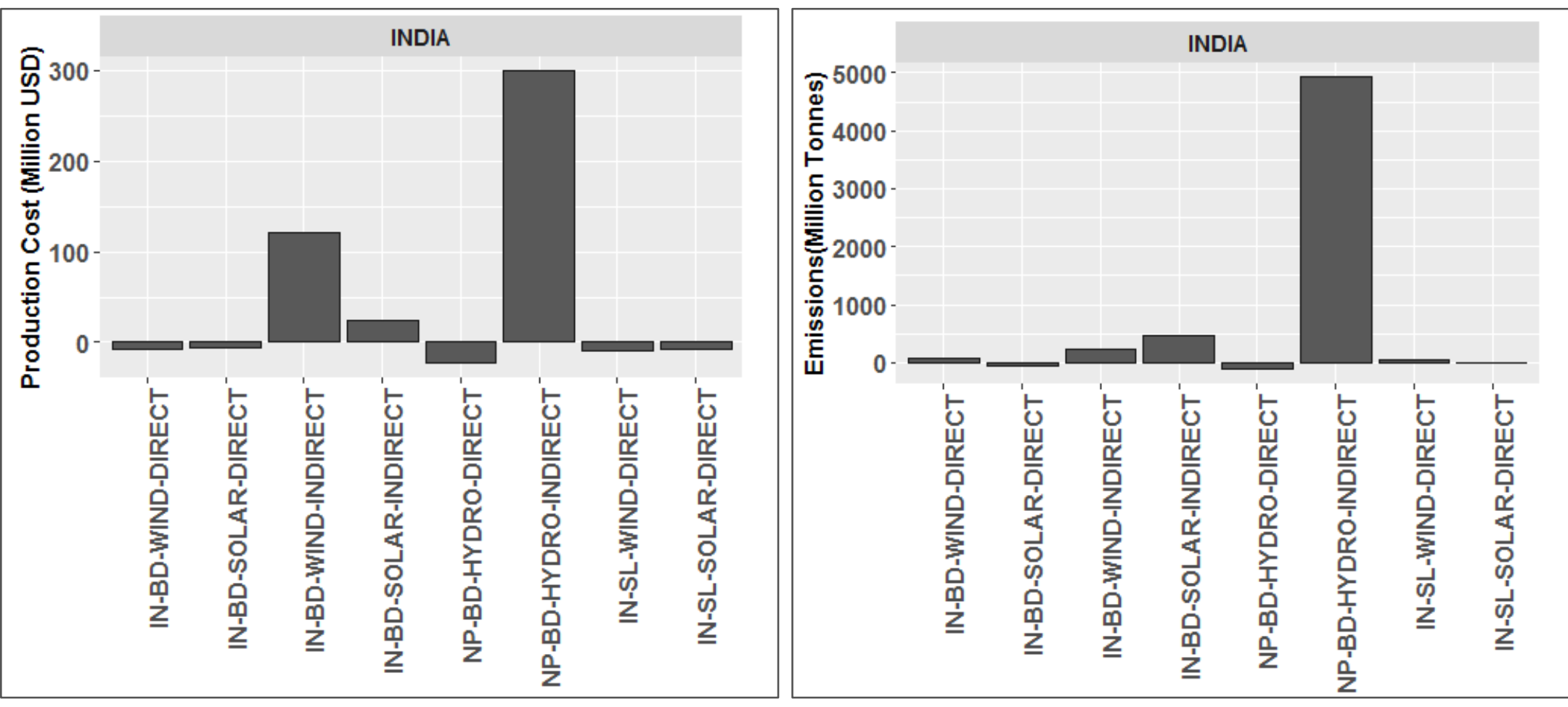

Negligible increase in production cost and emissions for India with renewable power transfer through HVDC from West Bengal (India) to Bangladesh.

Increase in wind generation in Tamil Nadu leads to redispatch of generation on account of transmission and generation limits when wheeling power to Bangladesh. 


\section{Generation Redispatch in Indian States}
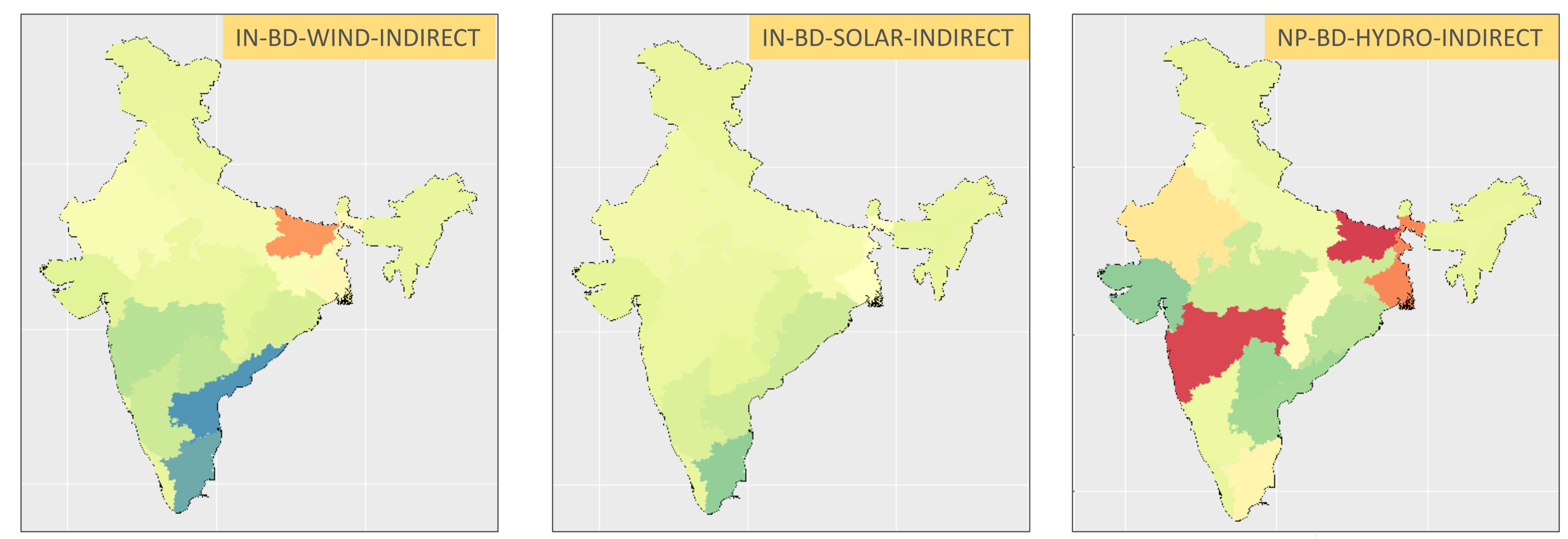

Redispatch of generation in case of indirect HVDC on account of transmission leads to marginal increase in generation of eastern and northern regions and marginal reduction in generation of western and southern regions. 
- India's national RE zones for wind power and solar photovoltaics (PV) and Nepal's hydropower could become regional green power resources if South Asian countries liberalize their rules for CBET.

- Integrated bulk power system in South Asia could improve resilience, increase benefits to customers, increase economic efficiency, and result in a greener grid.

- Combining domestic RE with imported wind, PV, and hydropower could accelerate decarbonization and reduce generation costs in South Asia.

- Wheeling power through India's ISTS appeared to offer the same operational benefits as building a separate line to bypass the ISTS altogether, as long as there is no institutional restraint on moving power between countries. 
- Able to balance system with $1 \mathrm{GW}$ wind, solar, or hydro contract.

- Value (production cost savings per unit of generation reduction)

- Wind most valuable, followed by hydro and solar

- Not much difference between direct and indirect HVDC

- $1 \mathrm{GW}$ wind contract:

- Reduces generation by $4.3 \%$, production cost by $9.5 \%$ and emissions by $5.5 \%$

- Displaces fuel oil by $12 \%$

- $1 \mathrm{GW}$ solar contract:

- Reduces generation by $2 \%$, production cost by $3.9 \%$ and emissions by $2.5 \%$

- Displaces fuel oil by $5.5 \%$

- $1 \mathrm{GW}$ hydro contract:

- Reduces generation by $7 \%$, production cost by $15 \%$ and emissions by $10 \%$

- Displaces fuel oil by $\% 20 \%$ 
- Able to balance system with $1 \mathrm{GW}$ wind or solar contract.

- Value (production cost savings per unit of generation reduction)

- $29 \%$ more value of solar than wind contract.

- Not much difference between direct and indirect HVDC

- $1 \mathrm{GW}$ wind contract

- Reduces generation by $7 \%$, production cost by $29 \%$ and emissions by $21 \%$

- Displaces gas generation by $47 \%$ and coal generation by $12 \%$

- $1 \mathrm{GW}$ solar contract

- Reduces generation by $1.4 \%$, production cost by $18 \%$ and emissions by $6.3 \%$

- Displaces gas generation by $33 \%$ 
- Negligible impact in terms of generation, production cost, and emissions.

- Wheeling RE through the Indian grid from Tamil Nadu to Bangladesh results in slightly less generation in southern and western region and slightly more generation in eastern and northern region. 
- Nepal's wealth of hydropower could be more useful to Nepal and its neighbors with greater market integration.

- Participation in an integrated regional power market could help Nepal achieve an economically optimal balance between importing and exporting power. 
- Impact of various levels of solar/wind import on the system of Bangladesh and Sri Lanka:

- The study has shown that Bangladesh and Sri Lanka are able to balance their power system with $1 \mathrm{GW}$ contract.

- What would be the impact on Bangladesh and Sri Lanka with more renewable import from India?

- What strategies could help these countries absorb more renewable generation from India ?

- Is there a level of imports that would reduce or delay the need for a major domestic infrastructure investment, or would significantly reduce the risk of future load shedding?

- Detailed analysis of impact within Bangladesh and Sri Lanka:

- This study has looked Bangladesh and Sri Lanka from macro level.

- A more detailed study could examine the impact of renewable imports on internal power flows, plant-level dispatch, plant load factors, and other unit-specific costs, such as startup and minimum run requirements.

- Including details within each country's network would also shed light on how RE imports might affect dispatch during the peak load day, maximum renewable penetration day, and other times that are operationally critical. 
- Best-suited import portfolio for Bangladesh and Sri Lanka:

- Different type of generation contract would have different impact.

- Would a portfolio/shaped product of renewables combined with any other type of conventional generation provide better value to the importing country than renewables alone?

- Would it be more cost-effective to bundle ancillary services with the contracted $\mathrm{RE}$, or to use domestic resources for the required ancillary service ?

- Impact with renewable contracts from different renewable zones:

- Different RE zones in India have different characteristics.

- Which zones tend to have the greatest value (production cost savings per unit of generation reduction) for the importing country? 


\section{References}

1) Palchak D., J. Cochran, A. Ehlen, B. McBennett, M. Milligan, I. Chernyakhovskiy, R. Deshmukh, et al. 2017a. "Greening the Grid: Pathways to Integrate 175 Gigawatts of Renewable Energy into India's Electric Grid, Vol. I - National Study." National Renewable Energy Laboratory (NREL), Lawrence Berkeley National Laboratory (Berkeley Lab), Power System Operation Corporation Limited (POSOCO) and U.S. Agency for International Development (USAID). https://www.nrel.gov/docs/fy17osti/68530.pdf.

2) McBennett, Brendan, Amy Rose, David Hurlbut, David Palchak, and Jaquelin Cochran. 2019. Cross-Border Energy Trade Between Nepal and India: Assessment of Trading Opportunities. Golden, CO: National Renewable Energy Laboratory. NREL/TP-6A20-72066. https://www.nrel.gov/docs/fy19osti/72066.pdf.

3) Hurlbut, David J.. 2019. Cross-Border Energy Trade between Nepal and India: Trends in Supply and Demand. Golden, CO: National Renewable Energy Laboratory.NREL/TP-6A20-72345. https://www.nrel.gov/docs/fy19osti/72345.pdf.

4) Bangladesh Power Development Board (BPDB). 2019. Annual Report 2018-19 https://www.bpdb.gov.bd/bpdb new/resourcefile/annualreports/annualreport 1574325376 Annual Report 201819.pdf.

5) Power Grid Company of Bangladesh Limited. Daily Operational Reports. http://pgcb.gov.bd/site/page/0dd38e197c70-4582-95ba-078fccb609a8/-.

6) Rose, Amy, Brendan McBennett, David Palchak, Jaquelin Cochran, H.M. Wijekoon, Buddhika Samarasekara, Randika Wijekoon. 2018. Cross-Border Electricity Trade between India and Sri Lanka: Impact on Power System Operations. Golden, CO: National Renewable Energy Laboratory. NREL/TP-6A20-71983.

https://www.nrel.gov/docs/fy19osti/71983.pdf.

7) Bhutan Power System Operator (BPSO). 2019. Quarterly reports. http://bpso.bpc.bt/category/quarterly/. 


\section{Thank You}

\section{www.nrel.gov}

\section{Contact Us:}

Mohit Joshi (Mohit.Joshi@nrel.gov)

David Hurlbut (David.Hurlbut@nrel.gov)

David Palchak (David.Palchak@nrel.gov)

NREL/PR-6A20-77029

This work was authored by the National Renewable Energy Laboratory, operated by Alliance for Sustainable Energy, LLC, for the U.S. Department of Energy (DOE) under Contract No. DE-AC36-08G028308. Funding provided by U.S. Department of State's Bureau of South and Central Asian Affairs Regional Connectivity Program. The views expressed herein do not necessarily represent the views of the DOE or the U.S. Government.

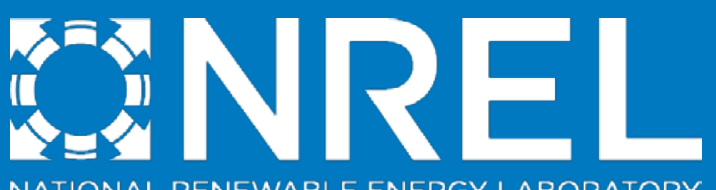

NATIONAL RENEWABLE ENERGY LABORATORY 